\title{
RADIO ECHO-SOUNDING STUDIES OF ENGLACIAL WATER MOVEMENT IN VARIEGATED GLACIER, ALASKA
}

\author{
By Robert Jacobel* and Charles Raymond
}

(Geophysics Program AK-50, University of Washington, Seattle, Washington 98115, U.S.A.)

\begin{abstract}
Radio-echo returns from internal reflectors were monitored for three weeks during surge motion on Variegated Glacier, Alaska in July 1982. A monopulse transmitter with $3 \mathrm{MHz}$ center frequency was fixed on the glacier surface near the equilibrium line. Data were recorded on magnetic tape approximately three times daily and contain both amplitude and phase information. The frequency spectrum of returned radiation from englacial scatterers shows peaks in the 12 to $30 \mathrm{MHz}$ range which place: constraints on the size and geometry of the scatterers. Timing of variations in the amplitude and frequency of returned radiation were found to coincide with changes in glacier velocity, basal water pressure, and surface melt rate. These changes in the echo pattern are interpreted in terms of the redistribution of water in englacial channels and cavities connected to the bec some distance down-glacier. This connection has large hydraulic resistance compared to a bore hole connected vertically to the bed. The inflow of water to the cavities from surface melt and rain and the drainage are generally in equilibrium except in times of changed surface input and during surge pulses. In the latter case, water may fill these cavities due to increased pressure at the bed associated with the motion pulse. The information obtained is therefore complementary to bore-hole water pressure levels but cannot duplicate it. This is apparently due to fundamental differences in the hydraulics of the natural cavity and conduit system, and a bore hole connected vertically to the bed.
\end{abstract}

RÉsumé. Les éludes de sondages par échos radio du mouvement de l'eau à l'intérieur du Variegated Glacier, Alaska. Les retours des échos radio des réflecteurs internes ont été suivis pendant trois semaines durant le mouvement de surge sur le Variegated Glacier, Alaska, en juillet 1982. Un émetteur mono impulsion, centré sur la fréquence de $3 \mathrm{MHz}$, était en station sur la surface du glacier près de la ligne d'équilibre. Les données ont été enregistrées sur des bandes magnétiques environ trois fois par jour et contiennent à la fois les informations d'amplitude et de phase. Le spectre de fréquence de vibrations renvoyées par les discontinuités intraglaciaires montrent des pics dans le domaine des 12 à $30 \mathrm{MHz}$ ce qui délimite la taille et la géométrie des discontinuités. La distribution des variations dans le temps des amplitudes et fréquences pour les vibrations en retour a été trouvée en coïncidence avec les changements de la vitesse du glacier, de la pression de l'eau à la base et de la vitesse de fonte en surface. Ces changements dans la forme de l'écho sont interprétés en terme de redistribution de l'eau dans les canaux glaciaires et les cavités reliées au lit à quelque distance à l'aval. Cette connection possède une résistance hydraulique quand on la compare à un trou

\section{IN TRODUCTION}

Radio echo-sounding has been used on temperate glaciers as a tool for determining ice thickness and bedrock profiles. The problem of scattering losses due to water and other dielectric impurities in the ice has been large circumvented by employing radars at frequencies on the order of a few $\mathrm{MHz}$ (Watts and England, 1976; Watts and Wright, 1981). Sti11, it is common with these systems to detect scattering due to inhomogeneities within the glacier, although this "noise" is normally well below the signal strengths returned from the bedrock. Goodman (1973) in a brief report, noted changes in the amplitude pattern of englacial scatter returns on time scales of one month, but a systematic study of this phenomenon has not heretofore been used to gain information about structures of strong dielectric contrast within a temperate glacier.

Water bodies in temperate ice are regions of the strongest dielectric contrast because of the large difference in relative permittivity between ice and

*Present address: Department of Physics, St Olaf College, Northfield, Minnesota 55057 , U.S.A. de forage relié verticalement au lit. L'apport d'eau aux cavités à partir de la fonte en surface et de la pluie est généralement équilibré par le drainage, sauf aux moments où l'arrivée depuis la surface change et pendant le impulsions de surge. Dans ce dernier cas, l'eau peut remplir ces cavités à cause de la pression accrue sur le lit par suite des à-coups de mouvement. L'information obtenue est cependant complémentaire de celle de la pression d'eau dans le trou de forage, mais elle ne peut la remplacer. Ceci est évidemment dû à la différence fondamentale en hydraulique entre la cavité naturelle et le système de conduit, et un trou de forage connecté verticalement au lit.

Zusammenfassung. Untersuchung der intraglazialen Wasserbewegung im Variegated Glacier, Alaska, mit Radar-Echolotungen. Im Juli 1982 wurden Radar Echos von inneren Reflexionsquellen drei Wochen lang während Ausbruchs-bewegungen am Variegated Glacier in Alaska aufgezeichnet. Ein Monoimpuls-Sender mit $3 \mathrm{MHz}$ Zentralfrequenz war an der Gletscheroberfläche nahe der Gleichgewichtslinie aufgestellt. Die Daten wurden etwa dreimal am Tag auf Magnetband registriert; sie enthalten Informationen sowohl über die Amplitude wie über die Phase. Das Frequenzspektrum der von intraglazialen Streuquellen reflektierten Strahlung zeigt Maxima im 12-30 MHz-Bereich, was Rückschlüsse auf Grösse und Geometrie der Streuquellen zulässt. Für das Auftreten von Schwankungen in der Amplitude und Frequenz der reflektierten Strahlung ergaben sich Übereinstimmungen mit Änderungen der Gletschergeschwindigkeit, des Wasserdrucks am Untergrund und der Schmelzrate an der Oberfläche. Diese Änderungen im Echoverlauf wurden als Folge der Umverteilung von Wasser in intraglazialen Kanälen und Hohlräumen, die mit dem Gletscherbett in einiger Entfernung gletscherabwärts in Verbindung stehen, gedeutet. Diese Verbindung weist im Vergleich zu einem vertikal zum Untergrund führenden Bohrloch höheren hydraulischen Widerstand auf. Der Zufluss von Wasser in die Hohlräume aus Schmelze und Regen von der Oberfläche steht im allgemeinen mit dem Abfluss im Gleichgewicht, nicht jedoch zu Zeiten wechselnden Zustroms von oben und während Ausbruchsimpulsen. Im letzteren Fall dürfte Wasser diese Hohlräume infolge der damit verbundenen Druckerhöhung am Untergrund füllen. Die gewonnene Information ähnelt daher der aus der Höhe des Wasserdrucks in Bohrlöchern, ist ihr jedoch nicht gleichzusetzen. Der Grund dafür liegt in den fundamentalen Unterscheiden zwischen den hydraulischen Verhältnissen des natürlichen Hohlraum- und Wasserführungssystems und einem senkrecht zum Gletscherbett führenden Bohrloch.

water at radar frequencies. Air voids are much weaker scatterers, since the contrast in refractive index is less than one-fifth as great. Therefore, radar is a potentially valuable tool for remote sensing of water and its movement within ice. Amplitude, phase, and spectral variations of scattered and reflective electro magnetic radiation can all provide information about the englacial structure. The present experiment was designed to detect regions of stored water within Variegated Glacier and to study how these changed with time.

Variegated Glacier is a surge-type glacier located in south-eastern Alaska near the head of Yakutat Bay. It last surged in 1964-65 and has been studied since 1973 (Bindschadler and others, 1977; Bindschadler, 1982; and papers in preparation by C.F. Raymond and S.D. Malone and by H. Engelhardt and W.B. Kamb). The present experiment was one of several which took place during July 1982 while the most recent surge was in its beginning stages. The radar observations can be correlated with other geophysical data collected on the glacier: basal water pressure, strain-rate, seismicity, and velocity, and this is crucial for their interpretation in terms of the glacier's hydraulics. 


\section{DESCRIPTION OF THE EXPERIMENT}

A monopulse radar transmitter was fixed on the glacier surface near the equilibrium line at about $8.3 \mathrm{~km}$ from the head of the glacier. The transmitting dipole antenna radiated at frequencies 0 to $100 \mathrm{MHz}$ peaked sharply at $3 \mathrm{MHz}$. Echo returns were received by an identical dipole antenna fixed in a parallel orientation $40 \mathrm{~m}$ away. These returns were fed to a sampling oscilloscope, connected in turn to an analog tape recorder which kept a record of the received waveform and the time of the recording. Figure 1

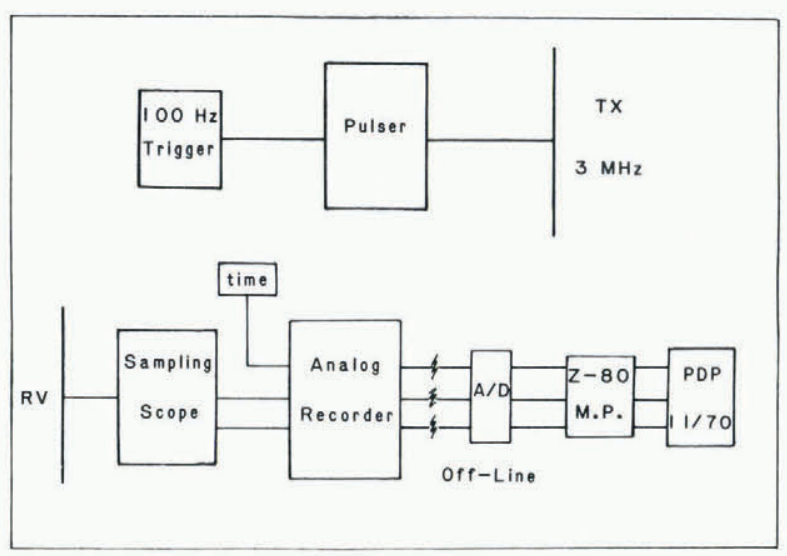

Fig. 1. Block diagram of the radio echo-sounding apparatus and data acquisition system.

shows a block diagram of the apparatus. Such an untuned receiver system records the unrectified electric field and thus both amplitude and phase information are available for later analysis. The sampling oscilloscope allows the megahertz-frequency radio returns to be "strobed-down" to audio frequencies suitable for recording on a tape recorder. The analog tapes were later digitized and subsequent analysis was done off-line by computer. Data were taken approximately three times daily for a period of $400 \mathrm{~h}$ beginning on 3 July.

The oscilloscope receiver was triggered each time on the arrival of the transmitted air-wave pulse, but the wave form actually recorded on tape correspond to a fixed time window of 0.3 to $2.3 \mu \mathrm{s}$ following. This window corresponds to a one-way path length in ice of 30 to $200 \mathrm{~m}$. The lower edge of the time window removed most of the large-amplitude air-wave pulse from the data record. The upper edge was chosen to reach to a depth below the lowest piezometric heights of the basal water system expected from earlier bore holes by Engelhardt and Kamb (paper in preparation). The bedrock depth in this portion of the glacier is known from seismic profiles and bore-hole studies, and is approximately $400 \mathrm{~m}$. Although no persistent attempts were made to record them, it is worth noting that no returns were identified from the bottom in this location, probably because of the strong scattering at shallower depths.

The monopulse of the transmitter was produced by a series of avalanching transistors, and transmitted power was not sensitive to possible power-supply variations. The dipole antennas used in the experiment were overdamped by resistive loading to prevent reflections and ringing in the system (Watts and England, 1976). Minor changes in antenna impedance from meteorologic variations would not be expected to affect the transmitted or received waveforms. Occasional monitoring of the airwave showed no noticeable gain changes. Over periods of hours the returned waveforms were highly repeatable over the recording time window, even when there were sudden changes in weather such as day to night temperature changes and heavy rain. Echoes were unaffected by small movements of the transmitter or receiver antennas and also were not sensitive to people nearby or equipment in the far field. Because of these design features of the system and our experience with it, we are confident that the major changes in echo waveforms described below were a consequence of changes beneath the glacier surface and not the system or the atmosphere.

In addition to the parallel antenna configuration described above, occasional recordings were made with the receiver antenna oriented perpendicular to the transmitter. These gave results qualitatively similar to those from the parallel configuration, but there were some distinct differences in the amplitude and frequency spectra implying scattering from at least a partly different set of echo sources. Although the orthogonal configuration is potentially useful for favoring a somewhat different geometry and provides additional information on the subsurface structure, it was not used frequently enough to warrant a thorough presentation of data and interpretation of the sources. However, the results from parallel and orthogonal antenna configurations are distinct enough to rule out system ringing as a major factor in the echo spectra and their changes.

\section{FEATURES OF RADIO-ECHO RE TURNS}

An example of one of the digitized waveforms recorded on 7 July $(109 \mathrm{~h})$ is shown in Figure $2 \mathrm{a}$. One notable feature evident in this figure and in all of
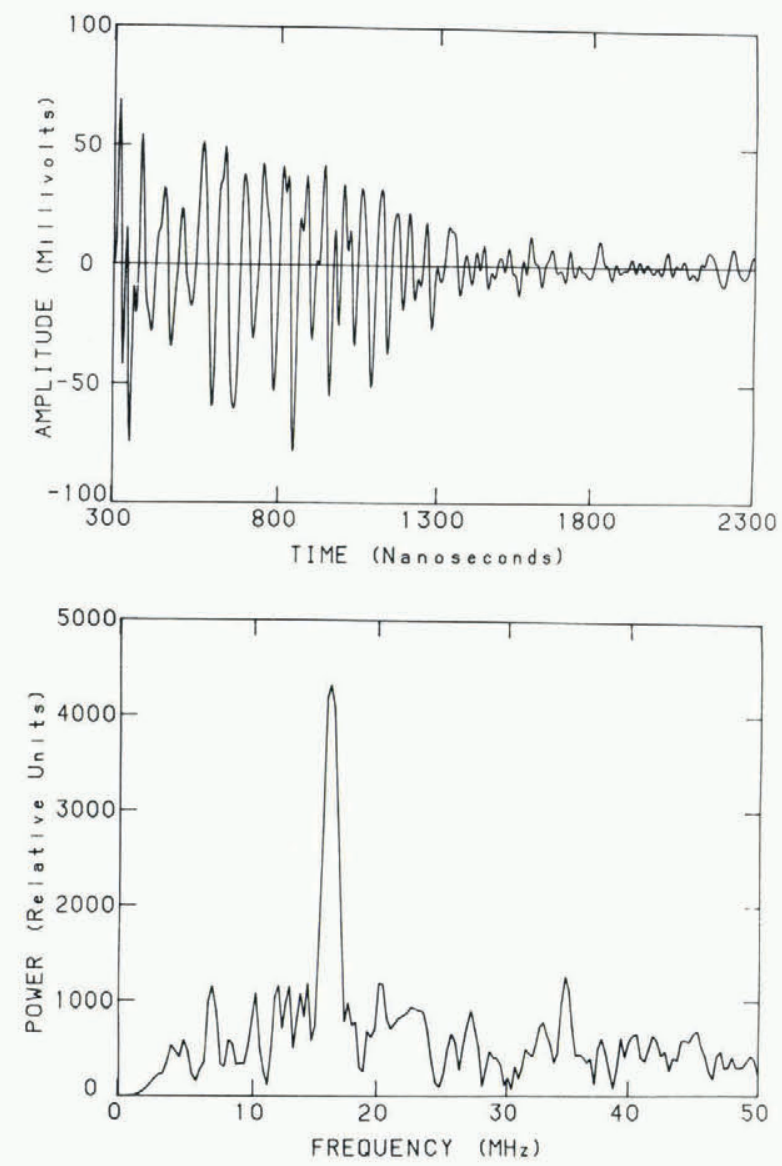

Fig. 2. (a) Amplitude-versus-time echo waveform on $?$ July $(109 \mathrm{~h})$ showing strong in-phase returns ("ringing") in the first microsecond.

(b) Frequency spectrum of the same waveform showing strong peaking of the returned energy at $16 \mathrm{MHz}$, characteristic of the size of the echo source. 
the returned waveforms is that their principal frequency content is in the range 12 to $30 \mathrm{MHz}$. This is significantly above the $3 \mathrm{MHz}$ central frequency of the input waveform. The physical processes giving rise to the returns evidently favor the scattering and reflecting at higher frequencies in the range. The frequency spectrum of this returned radiation should contain information about the size of the echo sources. For example, back-scattering crosssections for electromagnetic waves incident on a distribution of spherical scatterers (Mie scattering) of mean radius $1.0 \pm 0.5 \mathrm{~m}$ increase by two orders of magnitude between 5 and $10 \mathrm{MHz}$ (Watts and England, 1976). Scattering is generally strongest from source regions which are on the average larger than 0.1 times the wavelength of incident radiation (beyond the Rayleigh region). Thus, a wave packet composed of many incident frequencies undergoes preferential scattering by wavelength and the radiation returned has a frequency distribution characteristic of the size of the scatterers. In the present experiment the assumption of spherical Mie scattering centers would be an unjustified simplification, and the solution of the inverse problem of determining the exact size distribution of scatterers from the scattered frequency distribution is unfortunately not possible. However, the preferential return of higher frequencies (12 to $30 \mathrm{MHz}$ ) seen in the echoes reveals that scattering generally occurs from regions which on the average have dimensions of 1 to $2 \mathrm{~m}$.

The frequency spectrum obtained by fast Fourier transform of the amplitude-versus-time series displayed in Figure $2 \mathrm{a}$ is shown in Figure $2 \mathrm{~b}$. In addition to the general distribution of scattered radiation described above, this specific spectrum shows a single strong frequency component at $16 \mathrm{MHz}$. This is also apparent in the "ringing" seen in the
first microsecond of the time series of Figure $2 \mathrm{a}$. What appears to be happening in this case is that waves are being returned in phase from a reflector which selectively returns this frequency. This phenomenon is familiar to seismologists who see it when a water layer intervenes between their source and the region being studied. Multiple, in-phase reflections are returned from the layer and their frequency corresponds to the layer thickness. Other frequencies are returned out of phase, and on the average cancel each other or show up as lower amplitude returns. For constructive interference, the path length within the layer must equal an odd integral number of halfwavelengths. For near-normal incidence the width of the region is thus approximately one-quarter of a wavelength. In the present case these multiple reflections would arise from a water body with a thickness dimension of about $0.5 \mathrm{~m}$.

It is interesting to note that the power reflection coefficient for electromagnetic radiation of these frequencies at near normal incidence on an icewater boundary is about 0.5 . This coefficient gives the smoothest decrease in returned energy at each successive reflection from within a layer, in agreement with the general decline in amplitude of the ringing seen in these spectra. Other values of the power reflection coefficient yield sharp inflection points in the curve of energy returned verus reflection number at the second reflection which are not consistent with the data.

The question to be addressed next is, where is the water body located, or, more precisely, what is its depth and orientation? Unfortunately, the dipole nature of the radiation pattern will not allow a complete answer to this question. Although the radar is generally downward-looking, radiation returned from within the glacier at one instant of time can in principle originate from any point along an ellipsoid with the transmitter and receiver as foci. At distances considered in this study the ellipsoid approximates a sphere with its center midway between the transmitter and receiver on the surface. The precise location of the source considered above could thus, in principle, lie anywhere on a sphere with the reflecting portion of the body tangent to it. Since the strong ringing at $16 \mathrm{MHz}$ begins at the start of the returned waveform, the radius of this sphere can be no larger than $30 \mathrm{~m}$. Distances closer than this cannot be seen because the direct arrival of the air-wave pulse interferes and so has not been recorded.

Since the depth to this source cannot be determined unambiguously, the possibility that this body may be a surface crevasse should be considered. The requirement that the layer must be tangent to an equaltime ellipsoid at less than or equal to $30 \mathrm{~m}$ distance from the midpoint between the transmitter and receiver constrains the possible range of crevasse locations. During the present study no water-filled crevasses were present in the vicinity of the apparatus. In the first two weeks of running no crevasses appeared at all. Toward the end of the study a crevasse began to open in the area of the experiment, but it did not fill with water. Other arguments against a waterfilled crevasse producing these types of echo returns can be made from a consideration of the time variation of these reflections described in the next section. Similar reasoning would rule out englacial rock debris as the source. Experience with this monopulse radar system has also shown that at these frequencies it is relatively insensitive to air-filled crevasses. The possibility of a surface water layer producing these reflections must also be considered. During the melt season many glaciers develop a water table in the snow-pack and the previous year's porous firn. In 1982 Variegated Glacier received less than average amounts of snow-fall and, in the area where the radio echo-sounding experiment was conducted, July snow depths were only 1.5 to $0.5 \mathrm{~m}$ deep. Snow was underlain by old firn, and at times became water soaked when liquid input from melting and rain was slow to drain. Such a wet layer immediately below the experiment does not satisfy the geometrical requirements for producing in-phase reflections. The difference in path lengths for waves which might arrive by multiple reflection through the wet layer vary enormously and coherent multiple reflection is thus ruled out.

Figure $3 a, b$, and $c$ shows additional time-amplitude echo returns from 5,8 , and 10 July $(68,140$, $178 \mathrm{~h})$. The corresponding frequency spectra for these three time series are shown in Figure $3 d$, e, and $f$. These data runs were chosen to illustrate additional features of the echo pattern and to indicate how changes take place in time. However in each case the figure is representative of several data runs and thus does not depict singular or anomalous effects.

Figure $3 d$ reveals that on 5 July the echo return pattern was composed principally of two strong components at 14 and $17 \mathrm{MHz}$. The close proximity in frequency of these two components produces "beats" in the time series which are seen in Figure $3 a$. This strongly suggests that two refelectors of slightly different size are providing strong returns and interfering constructively at some times and destructively at others (beats). The distance of these two regions is approximately equal since the pattern of beats seen in the time series begins almost immediately. Apparently one of these bodies emptied its water by 7 July or water otherwise moved to produce the strong single-frequency pattern at $16 \mathrm{MHz}$ previously shown in Figure 2 .

Figure 3b shows the amplitude-time series recorded on 8 July $(140 \mathrm{~h})$, when the largest amplitude returns of the entire experiment were received. The corresponding frequency spectrum, Figure $3 e$, shows that a strong component still existed at $17 \mathrm{MHz}$, but it is broader and is accompanied by other strong components at both higher and lower frequencies. More importantly, the onset of strong ringing and high amplitudes is delayed noticeably compared to previous runs, and corresponds to a source distance of $60 \mathrm{~m}$. 


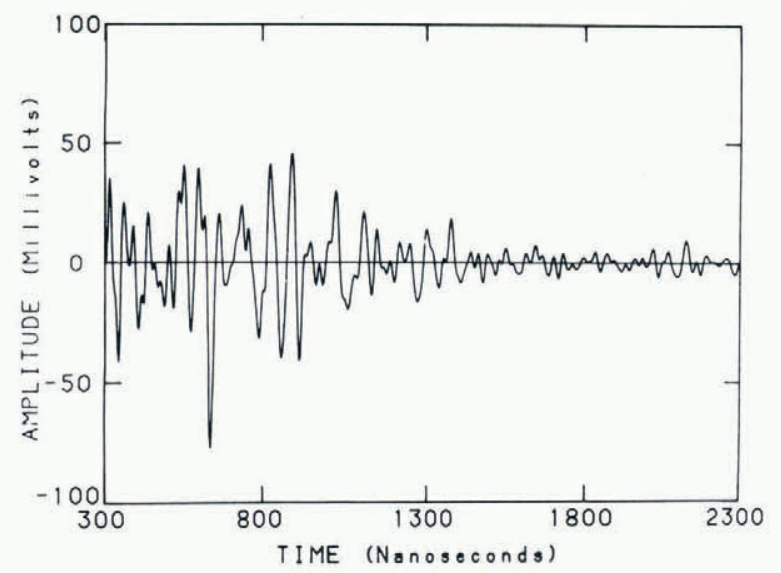

(a) Amplitude-versus-time waveform on $5 \mathrm{July}(68 \mathrm{~h})$. Beats can be seen due to echoes from two nearby sources.

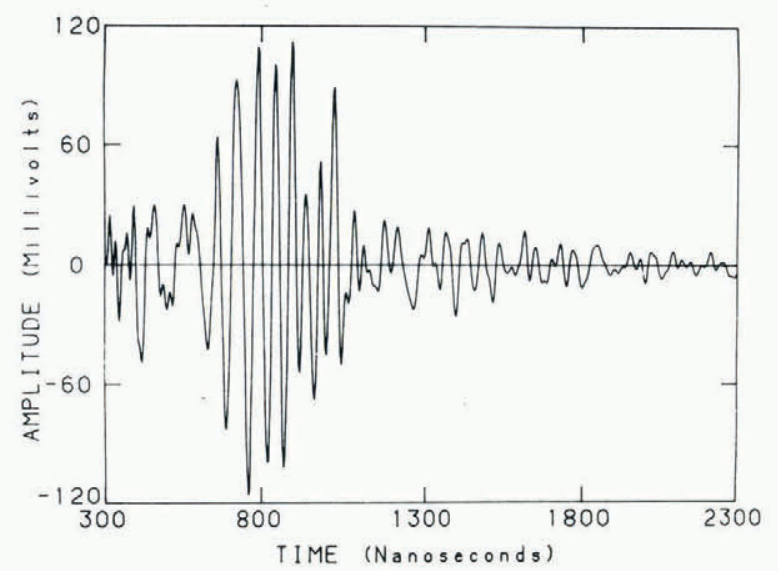

(b) Amplitude-versus-time waveform on 8 July $(140 \mathrm{~h})$ showing the strongest returns recorded and a shift in the onset of in-phase returns to greater timel distance.

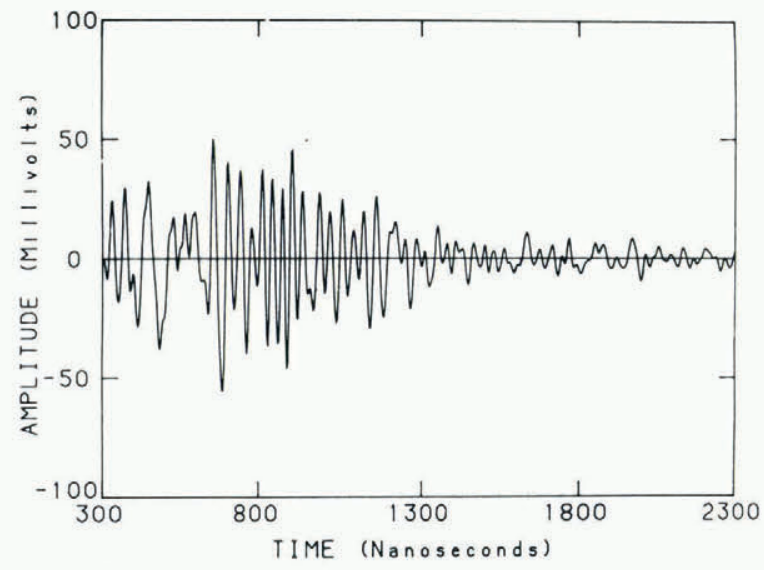

(c) Amplitude-versus-time waveform on $10 \mathrm{July}$ $(178 \mathrm{~h})$ after the surge pulse. Amplitude has decreased, and in-phase returns have shifted to higher frequencies.

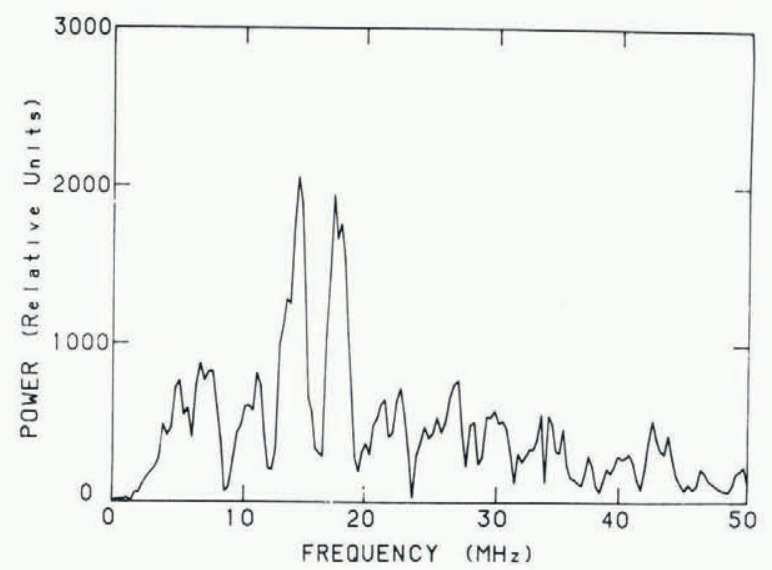

(d) Frequency spectrum of the waveform in (a) indicating that energy is returned primarily at two frequencies, 14 and $17 \mathrm{MHz}$.

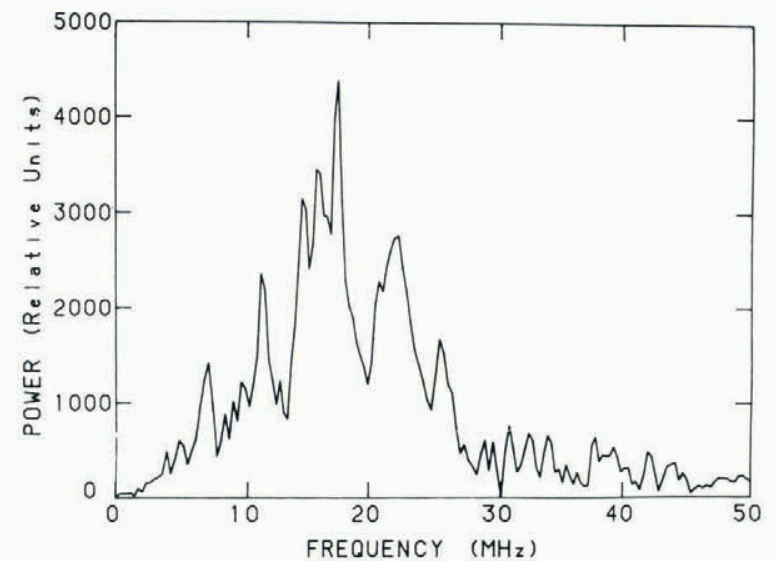

(e) Frequency spectrum of waveform in (b) indicating energy is being returned from a source with different frequency/size characteristics than the prominent one seen in Figure $2 b$.

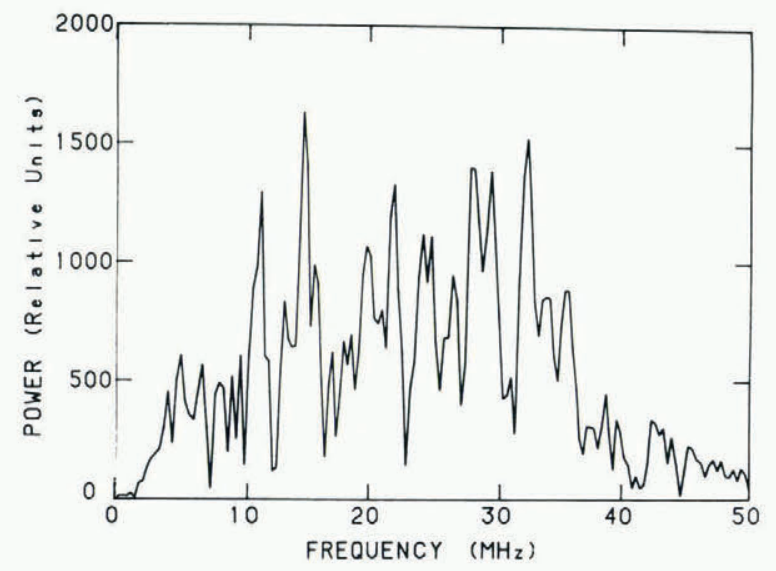

(f) Frequency spectrum of the waveform in (c). Energy is broadly distributed from 10 to $35 \mathrm{MHz}$ with proportionally more at higher frequencies than seen at any time previously.

Fig. 3. Representative amplitude-versus-time echo waveforms and corresponding frequency spectra from 5 to 10 July showing changes which occurred during a surge pulse on 8 July. 


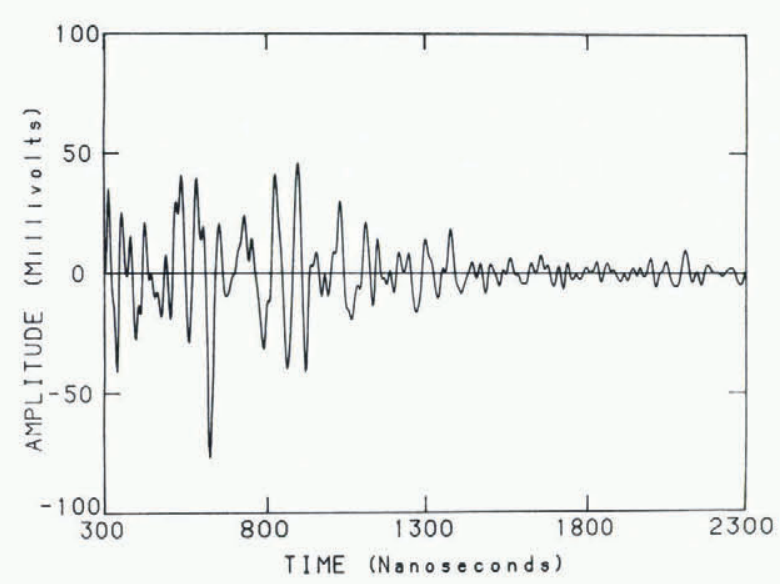

(a) Amplitude-versus-time waveform on $5 \mathrm{July}(68 \mathrm{~h})$. Beats can be seen due to echoes from two nearby sources.

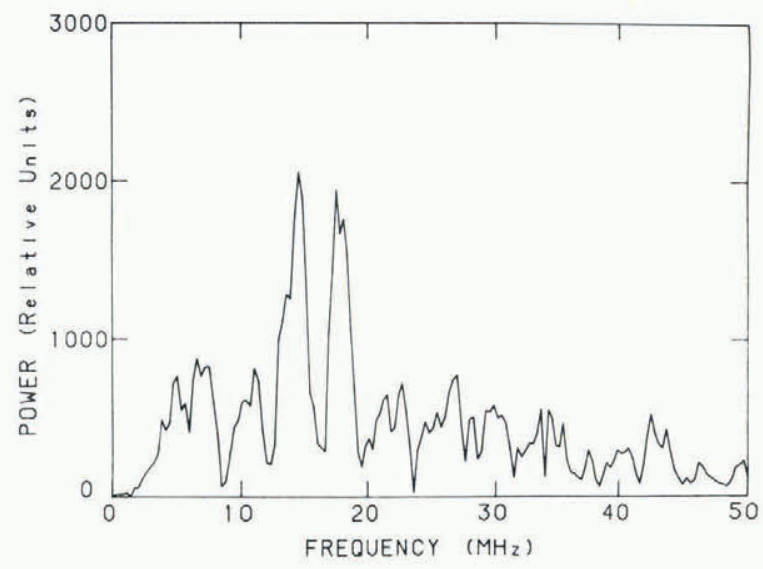

(b) Amplitude-versus-time waveform on 8 July $(140 \mathrm{~h})$ showing the strongest returns recorded and a shift in the onset of in-phase returns to greater timel distance.

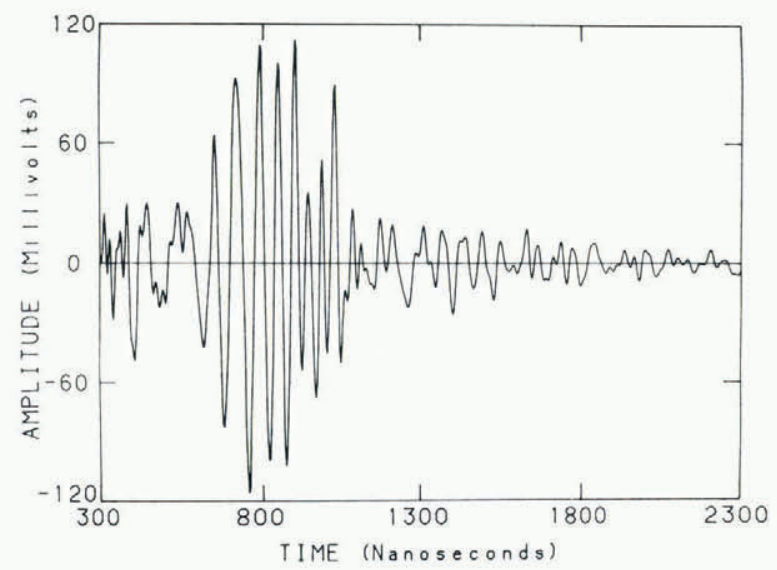

(c) Amplitude-versus-time waveform on $10 \mathrm{July}$ $(178 \mathrm{~h})$ after the surge pulse. Amplitude has decreased, and in-phase returns have shifted to higher frequencies.

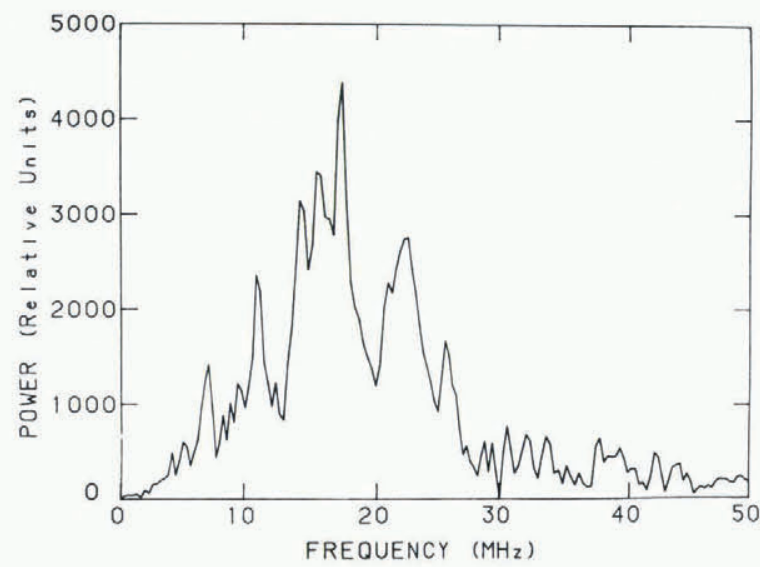

(d) Frequency spectrum of the waveform in (a) indicating that energy is returned primarily at two frequencies, 14 and $17 \mathrm{MHz}$.

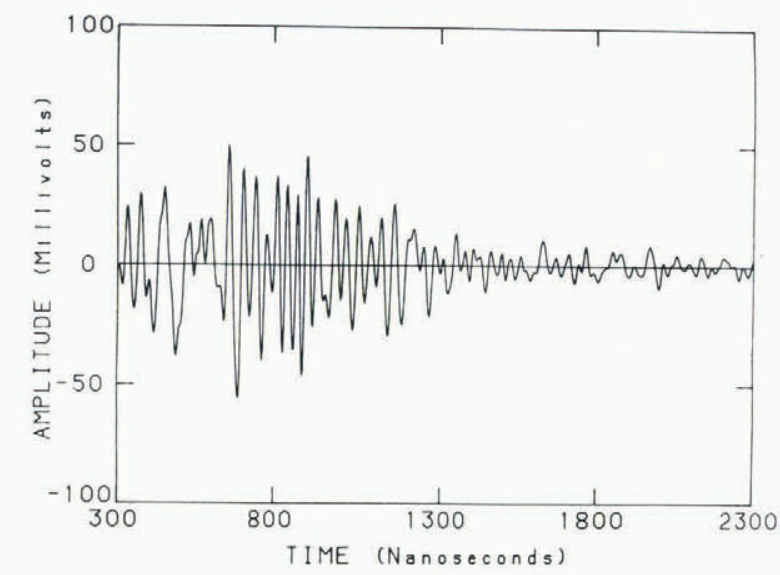

(e) Frequency spectrum of waveform in (b) indicating energy is being returned from a source with different frequency/size characteristics than the prominent one seen in Figure $2 b$.

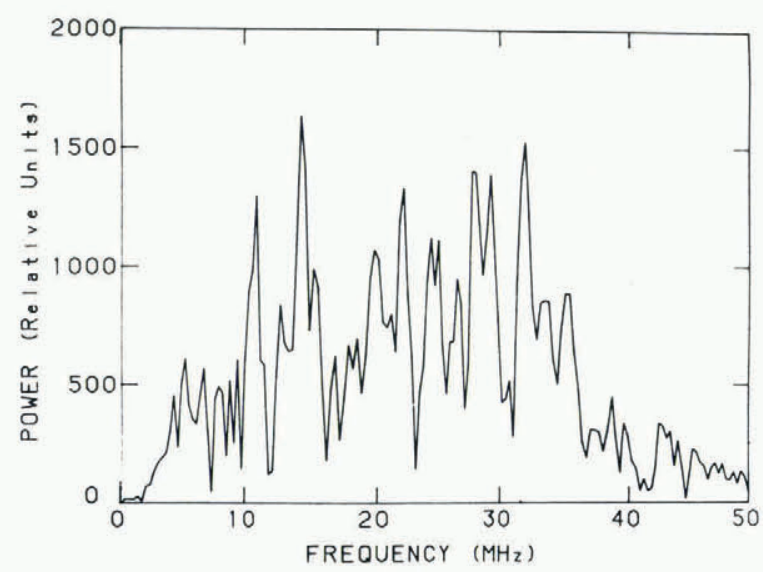

(f) Frequency spectrum of the waveform in (c). Energy is broadly distributed from 10 to $35 \mathrm{MHz}$ with proportionally more at higher frequencies than seen at any time previously.

Fig. 3. Representative amplitude-versus-time echo waveforms and corresponding frequency spectra from 5 to 10 July showing changes which occurred during a surge pulse on 8 July. 
By 10 July $(178 \mathrm{~h})$ the amplitude of radio-echo returns had decreased substantially as shown in Figure $3 c$. The corresponding frequency spectrum, Figure $3 f$, shows that there is no longer a single strong frequency component, and that compared to earlier spectra, proportionally more of the returned energy is found at higher frequencies. This suggests that water had drained from regions previously filled and the remaining water bodies were smaller.

\section{VARIATIONS OF RADIO ECHOES WITH TIME}

In order to study these variations systematically, and to facilitate comparison with other data collected on the glacier, the individual echo records were processed as follows:

The amplitude-time series were first run through a broad band-pass filter with a window from 5.0 to $50.0 \mathrm{MHz}$. This had the effect of removing the tail of the incident air-wave pulse which otherwise intruded slightly into the first 100 ns of the record. The high cut-off simply provided smoothing. The filtering process does not affect the location of peaks and minima in the time series. Other methods to remove the effect of the input waveform on the data commonly employ deconvolution techniques. In the present case, these are not necessary because the principal frequency contents of input and returned radiation are well separated and a simple filter removes the small amount of overlap. Next, the amplitude-time series were each searched for maximum and minimum points, and these were recorded along with the time in each series at which they occurred. These times (converted to distance) of the maxima and minima are plotted versus the date and time of each observation in Figure 4. Arrows pointing up indicate a maximum in the waveform; down arrows indicate a minimum. Each amplitude-time series like those shown in previous figures is thus represented by one column of arrows in Figure 4. A selection criterion, or cut, for the absolute value of the amplitude can be applied at different levels to study which returns are the strongest. For Figure 4 this cut is set at about one-half the value of the maximum returns received.

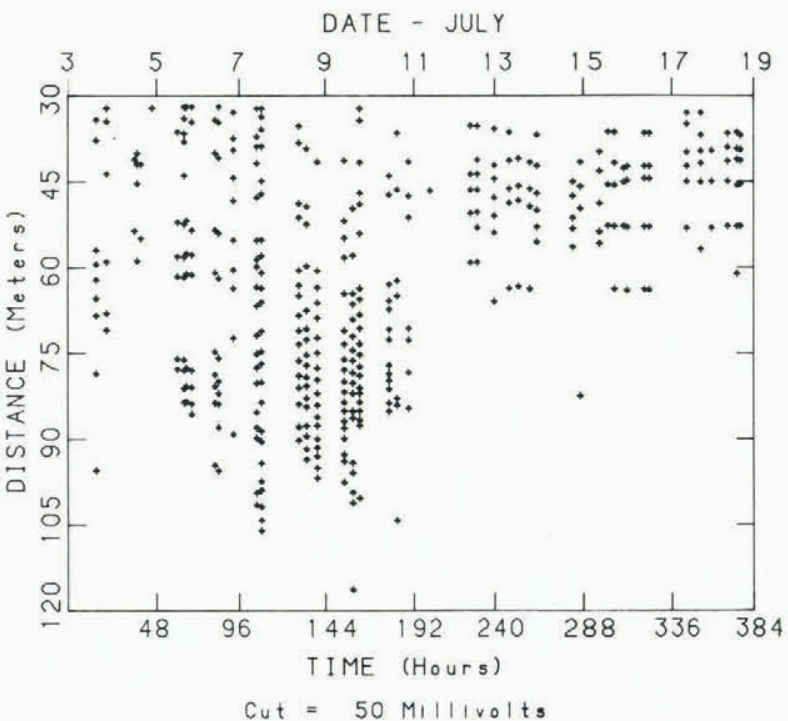

Fig. 4. Radio-echo time profile from 3 through 19 July showing changes in the echo sources due to the movement of englacial water. Ordinate scale is distance to the echo source. Up-pointing arrows represent a high-amplitude positive phase in the echo return; down-pointing arrows represent a strong negative

phase. Each column is derived from an amplitude-time series like those in Figures 2 and 3 . Note that data were taken on 5 and 11 July when echo amplitudes were generally below the cut threshold.
Several features can be seen in a plot like Figure 4 . The first is that changes in the echo pattern generally take place over periods of about ten hours. The amplitude-time series is quite repeatable from one record to the next a few hours later, but no return echoes are constant in time across the month. The time of greatest stability is between 300 and $380 \mathrm{~h}$ where there is a suggestion that the echo pattern has remained constant. There is also no apparent diurnal cycle in the record. The ringing described in the previous section is clearly seen around $140 \mathrm{~h}$ (and elsewhere) where the up and down arrows alternate with regular spacing. The beats seen in Figure $3 a$ are also apparent on 5 and 6 July $(60$ to $90 \mathrm{~h})$ before the pattern changes to one of a single strong return source on 7 July. Beginning on 9 July $(150 \mathrm{~h})$ the contribution of higher-frequency returns is also seen in the closer spacing of the arrows, and the decreasing amplitude is indicated as well.

Before considering what these changes mean glaciologically, it is useful to view this record in the context of two other studies that were done. A bore hole was drilled to the bed by the California Institute of Technology group approximately $1.3 \mathrm{~km}$ down-glacier from the radio echo-sounding experiment, and changes in the water pressure at the bed were monitored (personal communication from W.B. Kamb and H. Engelhardt). These are shown in Figure 5 superimposed on a radioecho-time profile where the same scale is used to

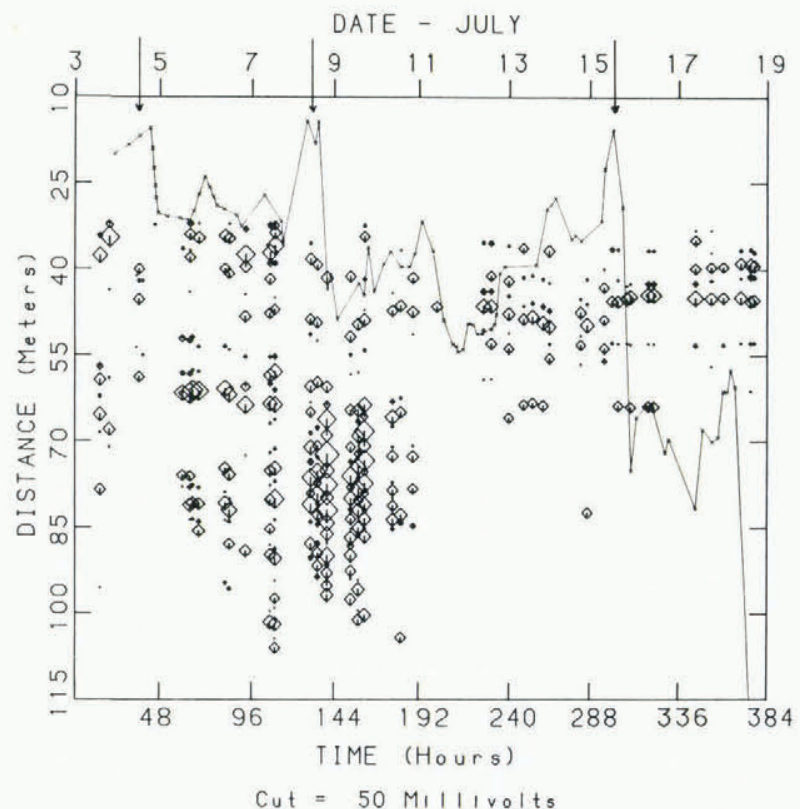

Fig. 5. Variation in water pressure at the bed as measured by water levels in a CIT bore hole (personal communication from W.B. Kamb and $H$. Engelhardt) superimposed on the radio-echo-time profile. Ordinate scale indicates both depth to the bore-hole water-level, and distance to the echo source as in Figure 4. Amplitude of the echo returns is indicated by the size of the plotting symbol. Arrows at the top of the figure show the dates of surge pulses. Minimum observable echo return distance is $30 \mathrm{~m}$.

indicate both distance (from echo sources) and depth (to water-level). Since the echo distances are not necessarily downward distances, no absolute comparison should be made between the two records. In addition, the bore hole is connected to the water system at the bed and presumably measures basal water pressure. The radio-echo experiment responds to water in cavities and channels $1.3 \mathrm{~km}$ up-glaicer in a system which may be only remotely connected to the bed. The purpose of displaying these two different kinds of 
data together is to facilitate a comparison of the timing of changes in each record.

Amplitude information, indicated in Figure 5 by the size of the diamond symbol, shows more clearly how the amplitude changes on a time scale of several weeks. The strongest returns come on 6 and 7 July, beginning at close distance, and on 8 and 9 July at greater than $60 \mathrm{~m}$. Not quite so apparent are times of very low echo return strength at $45 \mathrm{~h}$ and $200 \mathrm{~h}$ where data exist but no strong returns are seen.

Results of surface velocity measurements are also shown in Figure 5 for times during which the glacier velocity increased by more than a factor of two above the summer average. These times are indicated by the three arrows at the top of the figure. Surge pulses generally occurred over time scales of 10 to $20 \mathrm{~h}$, although the third one shown in the figure actually lasted from 13 to $15 \mathrm{July}$. These events are coincident with increases in seismic noise levels and increased strain-rate, and also show a very close correspondence with increases in water pressure at the bed (personal communication from W.B. Kamb and H. Engelhardt).

Using the water-pressure and velocity measurements displayed in Figure 5 , it is now appropriate to describe more fully time changes in the radio-echo amplitude pattern and to include information from the frequency spectra. In the discussion which follows, it will be useful to refer closely to Figure 5 and the features previously noted in Figures 3 and 4.

From 3 to 4 July the echo strength gradually decreased while water pressure at the bed rose. On 4 July the glacier had a substantial increase in velocity which was followed by a drop in water pressure at the bed and a decrease in velocity on 5 July. Radioecho return amplitude decreased substantially late on 4 July coincident with the peak in water pressure, but returned to higher levels and a qualitatively different return pattern on 5 July. From 5 to 6 July the radio-echo returns were characterized by contributions from two frequency components which exhibited beats in the time series as discussed in the previous section and shown in Figure $3 a$ and $d$. On 7 July the echo return energy shifted to a single frequency, and amplitudes increased, as shown previously in Figure 2 .

Beginning late on 7 July $(120 \mathrm{~h})$ the basal water pressure rose substantially again, and another large velocity pulse occurred on 8 July, which in turn was followed by a drop in the water pressure. Throughout this surge pulse the amplitude of radio-echo returns continued to increase as more energy was returned at a broader range of frequencies. Coincident with the rise in water pressure, the maximum amplitude of echo returns shifted to a new pattern with strong echoes coming from a greater distance. The drop in water pressure following this second velocity pulse coincided with the beginning of a gradual change in the echo pattern to one of decreasing amplitude, and a broader frequency distribution shifted toward higher frequencies. This sequence was shown in Figure 3 .

By the morning of 11 July $(200 \mathrm{~h})$ the echo strength decreased to the lowest levels recorded, and along with this water pressure at the bed also dropped to the lowest level yet seen. It is worth noting that on the night of 10 July $(190 \mathrm{~h})$ air temperature fell to below freezing, and surface input of water was cut off. Following $200 \mathrm{~h}$ on 11 July, echo return strength increased to modest levels as water pressure rose to a third maximum on 15 July. Frequency distributions of the returned energy from 11 to 15 July show a fairly strong contribution at $17 \mathrm{MHz}$, but do not peak in this region as was the case earlier. This is also evident from the time series where the ringing which characterized earlier runs is not seen.

Finally, on 15 July, coincident with another, more gradual velocity pulse beginning on the 13 July, water pressure dropped abruptly and did not again rise to previous levels. After this drop in water pressure, the radio-echo return pattern became very stable with a broader distribution of frequency components. These changes are summarized qualitatively in Table I which is a useful reference for the next section.

TABLE I. SUMMARY OF RADI0-ECHO RETURN VARIATIONS, VELOCITY, AND BORE-HOLE WATER-LEVEL CHANGES

Date

Amplitude

3-4 July

Strong returns at close distance decreasing sharply to a minimum late on 4 July

5-7 July

Strong amplitude returns at close distance increase

8 July

Strong returns shift to distances of $60 \mathrm{~m}$ and amplitude increases further

9-10 July Amplitude decreases gradually at all distances

11 July

Lowest levels recorded

12-15 July Moderate amplitude at close distance

16-19 July Very stable pattern with moderate amplitude at close distance

Frequency

Water pressure

Velocity

Strong components distributed from 12 to $18 \mathrm{MHz}$

Two distinct strong components at 14 and $17 \mathrm{MHz}$ shifting to a single sharp component at $16 \mathrm{MHz}$ on $7 \mathrm{July}$

Strong component at $16 \mathrm{MHz}$ becoming broader

Shift to broad dis tibution, contributions 15 to $30 \mathrm{MHz}$

\section{Broad distribution}

Broad distribution 10 to $30 \mathrm{MHz}$, some peaking 12 to $20 \mathrm{MHz}$

Broad distribution as above. Spectrum very stable
Rising to peak on 4 July. Sharp drop following motion pulse

Intermediate levels and variable

Rising to a peak on 8 July. Abrupt drop following motion pulse

Intermediate levels and variable

Drops to new minimum

Rising slowly to new peak on 15 July. Sharp drop to new low following velocity and 15 July event

Very low levels and

variable
Motion pulse on 4 July

Motion pulse on 8 July

crease 14 July 


\section{GLACIOLOGICAL INTERPRETATIONS}

The previous section shows that there are substantial variations in the amplitude and frequency distribution of the radio-echo returns from within the glacier. These changes occur along with variations in surface-water input, basal pressure, and ice straining, perhaps acting in combination. The question to be addressed now is what mechanisms may be responsible for these changes and what they mean with regard to the hydraulic system of the glacier. An attempt to answer it necessarily involves some speculation, since the radar remote sensing reveals only a limited picture of events occurring within the glacier.

Based on theoretical considerations, Shreve (1972) suggests that the internal hydraulic system may consist of an upward branching, arborescent network of conduits (schematized in Figure 6 ). If this conduit

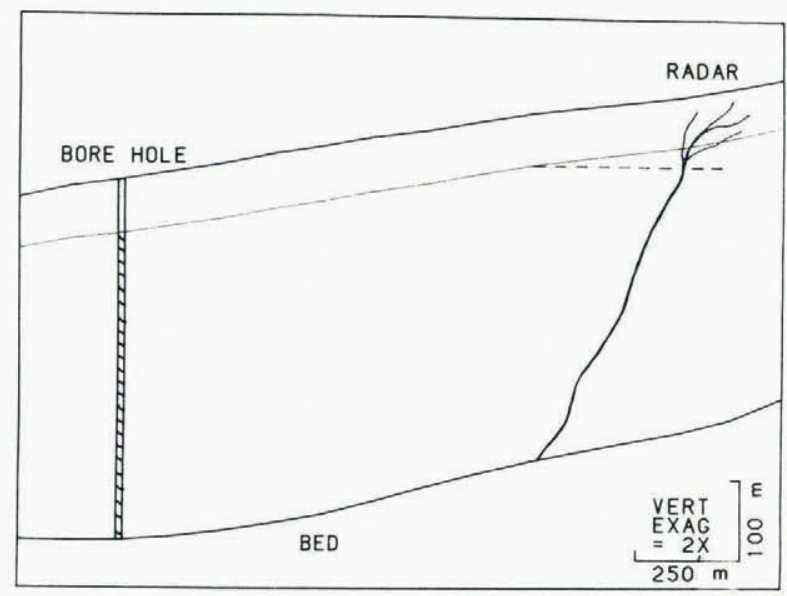

Fig. 6. Glacier longitudinal section showing piezometric water-levels in a natural channel connected down-glacier (pecked line), and in a bore hole connected to the basal water system. The figure indicates how variations in water-level as seen with a radio echo-sounder may not be the same as those obtained in a bore hole measuring basal water pressure.

system were to evolve so as to flow along the steepest hydraulic potential gradient in the intergranular water, then it would slope down-glacier at about $30^{\circ}$ from vertical, according to Shreve's equation and the geometry of the glacier. Based on this view, surface conduits at the radar site would reach the bed about $0.5 \mathrm{~km}$ down-stream. This would enable water beneath the radar at times to drain to levels below the piezometric height of a vertical water column connected at the bed, as indicated in Figure 6 . The absence of radar returns from water at depths near or below the piezometric level in portions of the data set is consistent with this picture of the hydraulic system.

In such a system, the very smallest passageways such as intergranular veins are expected to be filled with water continuously. On the other hand, water level in the larger passageways reaching the surface may vary as a result of changes in the basal water pressure, water input at the surface, or geometry of the passageways and associated hydraulic conductivity. If the water level in these larger passageways were to coincide to define a water table, this water table would cause a reflecting boundary of dielectirc contrast that could be sensed as it rises and falls. This was not seen in these observations in which the recognizable returns appear to be a consequence of discrete cavities at fixed distance. Therefore in Shreve's picture of the system, one must include cavities of at least decimeter dimensions which are connected to the drainage system by smaller passageways. To this view one may add the inference that either there is a substantial hydraulic resistance between the near surface and the bed, or that water may remain perched in cavities above the water table trapped by spillways; otherwise there would be better correlation of echo changes with the bore-hole waterlevel changes, and the strong near-surface scattering would have disappeared during time of low bore-hole water-levels.

The radio echo-sounding appears to have seen at least two principal scatterers: one at a distance of less than about $30 \mathrm{~m}$ (cavity B) and one at a distance of about $60 \mathrm{~m}$ (cavity $A$ ). Based on the foregoing discussion, cavity B scattered strongly except on 5 and 11 July. Strong scattering from cavity A was restricted to 8 July and $10 \mathrm{July}$ and was especially strong on 8 July. The apparent returns from distances at about $60 \mathrm{~m}$ prior to 8 July are characteristically different, as discussed above, and represent ringing from a closer source or sources. Presumably these intervals of strong scattering indicate when the cavities $A$ and $B$ contained substantial water. The changes in intensity and frequency of the scattered energy may have occurred as the amount of water changed, causing change in shape and size of the scattering water body.

One possible view is that these cavities contain water only when the "water table" is above them, that is a view in which voids below that "water table" are water-filled and those above it are empty. This could be compatible with observations if cavity $A$ is shallower than cavity $B$. The pattern of echo changes could then be explained as follows. Throughout the period of observation, cavity $B$ is generally waterfilled, but cavity $A$ is empty except following the rise to high basal water pressure on 8 July. Because of low surface input and basal water pressure on 5 and 11 July, the "water table" drops below both cavities and echoes disappear. The subsequent rise in basal water pressure on 6 and 12 July allows the "water table" to rise to a level sufficient to flood cavity B but not high enough to fill cavity $A$. A combination of relatively stable weather and basal water pressure after 16 July produced a stable configuration of water in cavity $B$.

Contrary to this view is the fact that cavity $A$ did not scatter strongly on 3,4 , or 16 July when basal water pressure was nearly as high as on 8 July. This might be explained by the longer duration of the high water pressure on $8 \mathrm{July}$, and the slightly higher level. More difficult to explain if $A$ is shallower than $B$ is the observation that cavity $B$ did not return energy strongly from 8 to 11 July while $A$ filled and emptied.

A second possible view is that these cavities may contain water even when they are above the "water table". The water content of the cavities is achieved by the balance of input and the factors controlling drainage. These latter factors may change with time as passageways evolve by thermodynamic and mechanical processes. For example, one could explain the pattern as follows. Cavity A fills from 8 to 10 July because of high input rate from the surface (and possibly flooding from beneath). It drains quickly on 11 July because input is very low, and it never refills because input does not rise high enough again. Cavity $B$ is filled almost all of the time because only small input is required to maintain its water content, but it too shows fluctuations to a lesser extent.

It does not seem possible to choose with certainty between these two views, but one of them, or some combination, seems likely to represent the actual circumstances. One other feature of the echo returns provides additional information and is worth noting. The absence of any strong diurnal variation implies that surface input rate differences on this time scale must be small in comparison with the volume of water responding to the radio echoes. Other features 
such as the fine-scale changes in frequency distribution and small apparent shifts in the distances to the scatterers require a more detailed model and further explanation.

\section{CONCLUSIONS}

The amplitude and frequency distributions of radio-echo returns from englacial water bodies are consistent with a model of cavities and connecting channels having dimensions of the order of $1 \mathrm{~m}$. Changes in the echoes appear to coincide with variations in surface-water input, basal water pressure and strain in the ice. However, these changes take place by an apparently complex interaction of several factors, and it is not possible to unravel unambiguously the principal causes of specific echo changes in this experiment. Interpretation would be helped by knowing the locations of cavities (i.e. depth), so a spatial survey should be done to locate them, or the radar deployed in a manner so as to provide this information.

In the present experiment, radio echo-sounding gives information which is complementary to that obtained from measuring water-levels in a connected bore hole. It reveals the existence of cavities containing variable amounts of water and having large hydraulic resistance between the surface and the bed. It also supports the view that the surface hydraulic system is connected longitudinally some distance down-glacier.

\section{ACKNOWLEDGEMENTS}

This work was supported by the National Science Foundation under Grant DPP 8200725, Amendment No. 5 . The field equipment for the radio echo-sounder was generously loaned to us by the U.S. Geological Sur- vey - Project Office Glaciology. The radio-echo data were digitized at St 0laf College utilizing electronics built by an undergraduate student, Chris Jacobsen. Bore-hole pressure data and velocity data were provided by Herman Engelhardt, Barclay Kamb, and their collaborators at the California Institute of Technology. We especially wish to thank our coworkers in the University of Washington Geophysics Program for their assistance in the field. One of us (R.J.) wishes to thank others in the department for their support and encouragement of this work during his sabbatical at the University of Washington.

\section{RFEFERENCES}

Bindschadler, R.A. 1982. A numerical model of temper ate glacier flow applied to the quiescent phase of a surge-type glacier. Journal of Glaciology, Vol. 28, No. $99, P .239-65$.

Bindschadler, R.A., and others. 1977. Geometry and dynamics of a surge-type glacier, by $R$.[A.] Bindschadler, W.D. Harrison, C.F. Raymond, and R. Crosson. Journal of Glaciology, Vol. 18, No. 79, p. 181-94.

Goodman, R.H. 1973. Time-dependent intraglacier structures. Journal of Glaciology, Vol. 12, No. 66, p. 512-13. [Letter.]

Shreve, R.L. 1972. Movement of water in glaciers. Journal of Glaciology, Vol. 11, No. 62, p. 205-14.

Watts, R.D., and England, A.W. 1976. Radio-echo sounding of temperate glaciers: ice properties and sounder design criteria. Journal of Glaciology, Vol. 17, No. 75, p. 39-48.

Watts, R.D., and Wright, D.L. 1981. Systems for measuring thickness of temperate and polar ice from the ground or from the air. Journal of Glaciology, Vol 27 , No. 97, p. 459-69. 